\title{
Radical abdominal trachelectomy for stage IB1 cervical cancer in Singapore
}

Yong Kuei Timothy $\underline{\operatorname{Lim}}^{1}$, MBBs, Mrcog, Yin Nin $\underline{C h i a}^{1}$, MBBS, Mrcog, Swee Chong $\underline{\text { Quek }}{ }^{1}$, MBBS, Frcog,

Kwai Lam $\underline{\text { Yam }}^{1}$, MBBS, FRCOG

\begin{abstract}
We report the first case of radical abdominal trachelectomy (RAT) and bilateral pelvic lymphadenectomy performed in Singapore, which was performed for a 35-year-old woman with stage IB1 cervical cancer, and review the current literature on this novel fertility-sparing surgery. Radical hysterectomy and pelvic lymphadenectomy are the conventional treatment for stage IB1 cervical cancer, but this results in the loss of fertility. However, the last 20 years have seen the development of fertility-sparing surgeries for young women with early-stage cervical cancer. Among these, laparoscopy-assisted radical vaginal trachelectomy (i.e. Dargent's procedure) is the most established technique, with good, documented long-term oncological and pregnancy outcomes. RAT, an alternative technique, was developed in the last decade. Although less than 200 reported cases worldwide have reported on the use of RAT, early data suggests good oncological outcome.
\end{abstract}

Keywords: abdominal radical trachelectomy, cervical cancer, fertility-sparing

\section{INTRODUCTION}

Radical abdominal hysterectomy and bilateral pelvic lymphadenectomy has been the traditional treatment for operable International Federation of Gynecology and Obstetrics $(\mathrm{FIGO})^{(1)}$ stage IB1 cervical cancer in young women for many decades, albeit with a resulting loss of fertility. Although the concept of fertility-sparing surgery for cervical cancer was first conceived by Aburel in 1932, ${ }^{(2)}$ it was only in 1987 that radical vaginal trachelectomy (RVT) was successfully developed for the treatment of FIGO stage IA2 to IB cervical cancer by Dargent et al in France. ${ }^{(3)}$ Since then, several authors have described favourable oncological and obstetric outcomes following the use of this technique in women aged between 21 and 45 years. $^{(3-6)}$ Conversely, the abdominal approach to radical trachelectomy has only been described in the literature in the last ten years. Herein, we present the first case of radical abdominal trachelectomy (RAT) performed in Singapore for stage IB1 cervical cancer in a woman who desired perservation of fertility. We also review the current literature on this novel technique.

\section{CASE REPORT}

A 35-year-old woman with stage IB1 cervical cancer diagnosed on cone biopsy was referred to a colposcopy clinic for a Pap smear, which revealed adenocarcinoma in situ in July 2010. Colposcopy revealed a large ectropion with a focus in the posterior lip, which was suspicious for adenocarcinoma in situ. Laser cone biopsy was performed and histopathology revealed a well-differentiated adenocarcinoma of the cervix measuring $16 \mathrm{~mm} \times 14 \mathrm{~mm}$. The radial margins were involved, but there was no lymphovascular space involvement. Chest radiography and magnetic resonance imaging of the abdomen and pelvis did not reveal any distant metastases. The patient shared her desire to retain fertility as she did not have any children. She was appropriately counselled, and subsequently consented to undergo RAT and bilateral pelvic lymphadenectomy in August 2010.

RAT was performed based on the technique described by Abu-Rustum et $\mathrm{al}^{(2)}$ with some modifications (Figs. 1a-e). The procedure was carried out through a Maylard incision. Development of the obturator, paravesical and pararectal spaces was carried out, followed by systematic bilateral pelvic lymphadenectomy. The patient's pelvic lymph nodes, which were sent for histological frozen sectioning, were negative for malignancy. Next, the urinary bladder was mobilised down to the mid-vagina. The infundibulopelvic ligaments, which contain the ovarian vessels, were kept intact. A uterine clamp was used to manipulate the uterus and avoid damage to the fallopian tubes and ovarian vessels. The uterine arteries were ligated at its origin from the internal iliac arteries. The pouch of Douglas was entered and the uterosacral ligaments were taken. Both ureters were mobilised down to the base of the bladder before the parametrium could be taken.

The vagina was entered with the aid of a LiNA McCartney Tube $^{\mathrm{TM}}$ (LiNA Medical, Devon, UK). A vaginal cuff of $2 \mathrm{~cm}$ was taken. Clamps were then placed at the level of the internal os and the cervix was amputated at about $5 \mathrm{~mm}$ below the level of the internal cervical os. A shaved margin of the remaining endocervix was sent for frozen sectioning to determine the resection margins. Once the margins were revealed to be negative for malignancy on histopathology, a permanent cerclage was placed using Ethibond ${ }^{\mathrm{TM}} \# 0$ suture (Ethicon Inc, NJ, USA)

${ }^{1}$ Department of Gynaecologic Oncology, KK Women's \& Children's Hospital, Singapore

Correspondence: Dr Lim Yong Kuei Timothy, Consultant, Department of Gynaecologic Oncology, Level 6, Women's Tower, KK Women's \& Children's Hospital, 100 Bukit Timah Road, Singapore 229899. yongkuei@hotmail.com 

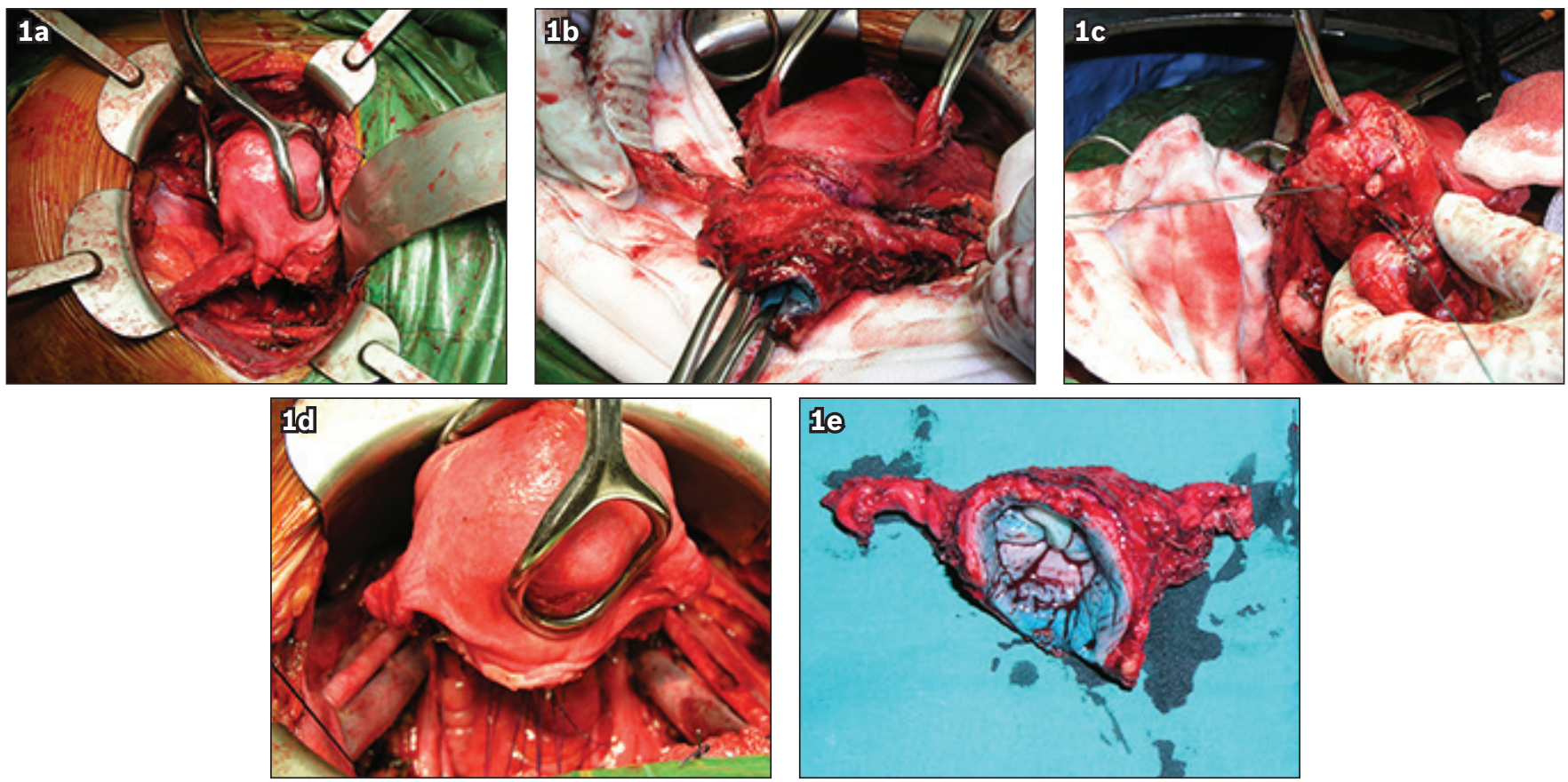

Fig. 1 Operative photographs of radical abdominal trachelectomy (RAT) show (a) preservation of the infundibulopelvic ligament and manipulation of the uterus with a uterine clamp; bilateral pelvic lymphadenectomy and ligation of the uterine vessels at the origin were performed; (b) exterioration of the cervix with a $2-\mathrm{cm}$ vaginal cuff; the cervix was amputated at approximately $5 \mathrm{~mm}$ from the internal os; and (c) permanent cerclage placement around the internal os with a Hegar ${ }^{\mathrm{TM}}$ size 4 dilator (Cooper Surgical, Trumbull, USA), maintaining patency. Operative photographs show (d) the uterine body reanastomosed with the vagina using several interrupted Vicryl ${ }^{\mathrm{TM}} 2 / 0$ sutures (Ethicon Inc, New Jersey, USA); care was taken to ensure that the uterus was well perfused; (e) an RAT specimen.

and the uterine corpus was reattached to the upper vagina with sutures. Prior to closure, we ensured that the uterine fundus had no evidence of ischaemia. Histopathological analysis revealed that the resection margins were clear, with no metastasis to the pelvic lymph nodes. The patient did not require any adjuvant treatment following surgery.

The patient was initially followed up on a biweekly basis for the first two months to ensure patency of the cervical os, and her menstruation resumed two months after surgery. Fig. 2 shows the colposcopic photograph of the patient's neocervix six months after surgery. The patient was subsequently followed up on a trimonthly basis, and has been disease-free for the past 18 months at the time of writing.

\section{DISCUSSION}

RAT is a relatively newer technique than RVT, with less than 200 cases reported in the medical literature. ${ }^{(6)}$ Nevertheless, there has been an increasing number of cancer centres around the world using RAT due to its shorter learning curve, which is attributed to its similarity to traditional Wertheim's radical hysterectomy, and the possibility of removing more parametrial tissue via this procedure than a vaginal approach. ${ }^{(2,7-10)}$

The eligibility criteria for RAT were adapted from that of RVT to include women aged $<40$ years, those with a strong desire for fertility, cervical cancer from FIGO stage IA2 to IB1, histological examination showing squamous cell carcinoma or adenocarcinoma, tumour size $<2 \mathrm{~cm}$ (debatable for abdominal approach), no involvement of the upper endocervical canal, and negative for metastasis to the pelvic lymph nodes. ${ }^{(2)}$

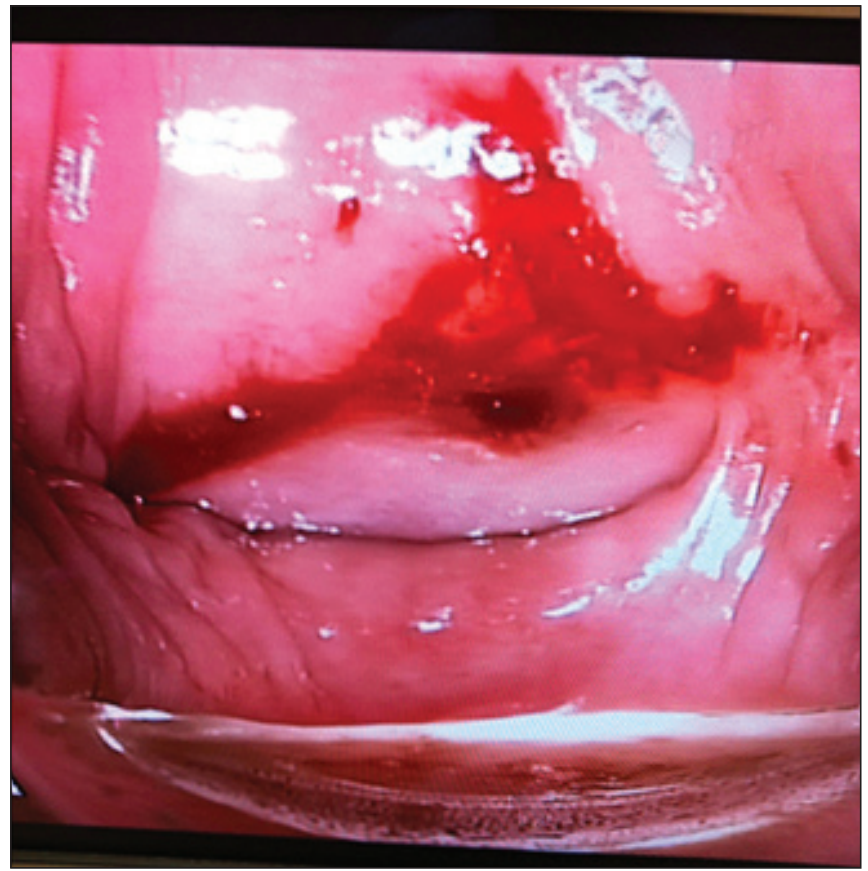

Fig. 2 Colposcopic photograph shows the neocervix six months after surgery.

Modification of the classical RAT procedure has been described in the literature. ${ }^{(7,10)}$ Evidence indicates that uterine perfusion can be maintained by the infundibulopelvic ligaments that contain the ovarian vessels, as demonstrated in our patient. ${ }^{(2)}$ Other authors have opted to preserve the uterine arteries by ligating the descending branch to the cervix or reanastomosing the uterine vessels. ${ }^{(7,10)}$ The role of the cervical cerclage is also controversial, with some authors preferring to insert a permanent 
Table I. Oncological and pregnancy outcomes of radical abdominal trachelectomy (RAT) in previously reported studies.

\begin{tabular}{|c|c|c|c|c|c|c|c|c|c|c|}
\hline $\begin{array}{l}\text { Study } \\
\text { (yr of study) }\end{array}$ & $\begin{array}{l}\text { No. of } \\
\text { RATs }\end{array}$ & $\begin{array}{c}\text { Mean age } \\
\text { of cohort } \\
\text { (yrs) }\end{array}$ & $\begin{array}{c}\text { Median } \\
\text { follow-up } \\
\text { period (mths) }\end{array}$ & $\begin{array}{c}\text { Recurrence } \\
\text { of cervical } \\
\text { cancer* }^{*}\end{array}$ & $\begin{array}{l}\text { No. of } \\
\text { deaths }\end{array}$ & Conception* & Miscarriage* & $\begin{array}{l}\text { Delivery at } \\
<37 \text { wks of } \\
\text { gestation* }\end{array}$ & $\begin{array}{l}\text { Delivery at } \\
>37 \text { wks of } \\
\text { gestation* }\end{array}$ & $\begin{array}{c}\text { No. of } \\
\text { ongoing } \\
\text { pregnancy }\end{array}$ \\
\hline $\begin{array}{l}\text { Abu-Rustum et al } \\
(2006)^{(2)}\end{array}$ & 15 & 33 & 12 & NA & 0 & $13.3(2 / 15)$ & $50(1 / 2)$ & $0(0 / 2)$ & $0(0 / 2)$ & 1 \\
\hline $\begin{array}{l}\text { Ungár et al } \\
(2005)^{(7)}\end{array}$ & 30 & 30.5 & 47 & $0(0 / 30)$ & 0 & $43.3(13 / 30)$ & $30.7(4 / 13)$ & $7.7(1 / 13)$ & $38.5(5 / 13)$ & 3 \\
\hline $\begin{array}{l}\text { Cibula et al } \\
(2009)^{(8)}\end{array}$ & 17 & 32.4 & 21.2 & $5.9(1 / 17)$ & 0 & $35.3(6 / 17)$ & $16.7(1 / 6)$ & $33.3(2 / 6)$ & $50(3 / 6)$ & 0 \\
\hline $\begin{array}{l}\text { Nishio et al } \\
(2009)^{(9)}\end{array}$ & 61 & 33 & 27 & $9.8(6 / 61)$ & 0 & $6.6(4 / 61)$ & $0(0 / 4)$ & $50(2 / 4)$ & $50(2 / 4)$ & 0 \\
\hline $\begin{array}{l}\text { Li et al } \\
(2011)^{(10)}\end{array}$ & 59 & 29.5 & 22.8 & $0(0 / 59)$ & 0 & $3.4(2 / 59)$ & NA & NA & NA & 2 \\
\hline $\begin{array}{l}\text { Pajera et al } \\
(2008)^{(11)}\end{array}$ & 14 & 30 & 32 & $0(0 / 14)$ & 0 & $21.4(3 / 14)$ & $0(0 / 3)$ & $33.3(1 / 3)$ & $66.7(2 / 3)$ & 0 \\
\hline $\begin{array}{l}\text { Olawaiye et al } \\
(2009)^{(12)}\end{array}$ & 10 & 31.7 & 28 & $0(0 / 10)$ & 0 & $40(4 / 10)$ & $25(1 / 4)$ & $25(1 / 4)$ & $25(1 / 4)$ & 1 \\
\hline
\end{tabular}

${ }^{*}$ Data is presented as \% (proportion). NA: not available; RAT: radical abdominal trachelectomy

cerclage at the time of surgery or during pregnancy. ${ }^{(2)}$ In this case, we opted to insert the Ethibond suture at the level of the internal os after trachelectomy.

The general complication rate for RAT has been reported to be similar to that of radical abdominal hysterectomy. ${ }^{(6)}$ Specific complications for radical trachelectomy include cervical stenosis, amenorrhoea, cerclage expulsion, and an increased risk of spontaneous abortion and premature delivery. ${ }^{(6)}$ Normal vaginal delivery is absolutely contraindicated for RAT, and pregnancies have to be delivered via classical Caesarean section for these patients. In a large review of patients undergoing RAT $(n=147)$ and RVT ( $\mathrm{n}=618$ ) by Rob et al in 2011, it was found that the oncological outcome was good for the RAT group, with only $7(4.8 \%)$ recurrences reported, similar to the recurrence rate of $4.7 \%$ in the RVT group. ${ }^{(6)}$ Recurrence rate, however, differed when the size of tumour was taken into account $-1.9 \%$ for tumours less than $2 \mathrm{~cm}$ in size and $20 \%$ for tumours measuring more than $2 \mathrm{~cm}$. ${ }^{(6)}$ These findings draw attention to the fact that fertilitysparing surgeries should be reserved for tumours less than $2 \mathrm{~cm}$ in size. Interestingly, to date, no deaths have been reported among patients who had undergone RAT.

With regard to pregnancy outcome, while there were 32 conceptions in the 30 (15.5\%) women who underwent RAT, only 20 live births were reported, including 7 (35\%) women who gave birth prematurely. ${ }^{(6)}$ Conversely, in patients who underwent RVT, there were 300 conceptions in 237 (30\%) women, with 190 live births and 38 (20\%) premature deliveries. ${ }^{(6)}$ The fertility outcome of RAT thus appears to be inferior to that of RVT. ${ }^{(6)}$ According to a study by Nishio et al, the relatively lower pregnancy rate among patients who underwent RAT may be due to cervical factors, chronic endometritis, and the larger volume of cervix being resected in this procedure. ${ }^{(9)}$ Table I presents the oncological and pregnancy outcomes of patients reported to have undergone RAT in the literature. . $^{2,7-9,11,12)}$

The laparoscopic or robotic approach to radical trachelectomy has recently been described to be associated with encouraging results in the medical literature. ${ }^{(13,14)}$ Reports of less radical fertility-sparing surgeries for cervical cancer of FIGO stage IA2 to IB1, including conisation or simple trachelectomy with or without pelvic lymphadenectomy, have also recently been published. ${ }^{(6)}$ The role of neoadjuvant chemotherapy before commencing fertility-sparing surgery is also currently being explored. ${ }^{(15)}$ However, large multicentre studies on these novel approaches are needed.

In this report, we presented the first case of RAT performed in Singapore for a young woman with stage IB1 cervical cancer who desired preservation of fertility. Our results suggest that RAT may be a viable fertility-sparing option for selective patients with early-stage cervical cancer.

\section{REFERENCES}

1. Pecorelli S. Revised FIGO staging for carcinoma of the vulva, cervix, and endometrium. Int J Gynaecol Obstet 2009; 105:103-4.

2. Abu-Rustum NR, Sonoda Y, Black D, et al. Fertility-sparing radical abdominal trachelectomy for cervical carcinoma: technique and review of the literature. Gynecol Oncol 2006; 103:807-13.

3. Dargent D, Brun JL, Roy M, Remi I. Pregnancies following radical trachelectomy for invasive cervical cancer. Gynecol Oncol 1994; 52:105.

4. Dargent D, Martin X, Sacchetoni A, Mathevet P. Laparoscopic vaginal trachelectomy a treatment to preserve the fertility of cervical carcinoma patients. Cancer 2000; 88:1877-82.

5. Shepherd JH, Spencer C, Herod J, Ind TE. Radical vaginal trachelectomy as a fertility-sparing procedure in women with early-stage cervical cancer-cumulative pregnancy rate in a series of 123 women. BJOG 2006; 113:719-24.

6. Rob L, Skapa P, Robova H. Fertility sparing surgery in patients with cervical cancer. Lancet Oncol 2011; 12:192-200.

7. Ungár L, Pálfalvi L, Hogg R, et al. Abdominal radical trachelectomy: a fertility-preserving option for women with early cervical cancer. BJOG 2005; 112:366-9.

8. Cibula D, Sláma J, Svárovský J, et al. Abdominal radical trachelectomy in fertility sparing treatment of early stages cervical cancer. Int J Gynecol Cancer 2009; 19:1407-11.

9. Nishio H, Fujii T, Kameyama K, et al. Abdominal radical trachelectomy as a fertility sparing procedure in women with early stage cervical cancer in a series of 61 women. Gynaecol Oncol 2009; 115:51-5.

10. Li J, Li Z, Wang, $\mathrm{H}$ et al. Radical abdominal trachelectomy for cervical malignancies: surgical, oncological and fertility outcomes in 62 patients. Gynecol Oncol 2011; 121:565-70. 
11. Pareja R, Ramirez PT, Borrero MF et al. Abdominal radical trachelectomy for invasive cervical cancer: A case series and literature review. Gynecol Oncol 2008; 111:438-43.

12. Olawaiye A, Del Carmen M, Tambouret $R$, et al. Abdominal radical trachelectomy: Success and pitfalls in a general gynecologic oncology practice. Gynecol Oncol 2009; 112:506-10.

13. Nick AM, Frumovitz MM, Soliman PT, Schmeler KM, Ramirez PT. Fertility sparing surgery for treatment of early stage cervical cancer: open vs. robotic radical trachelectomy. Gynecol Oncol 2012; 124:276-80.

14. Kim JH, Park JY, Kim DY, et al. Fertility-sparing laparoscopic radical trachelectomy for young women with early stage cervical cancer. BJOG 2010; 117:340-7.

15. Maneo A, Chiari S, Bonazzi C, Mangioni C. Neoadjuvant chemotherapy and conservative surgery for stage IB1 cervical cancer. Gynecol Oncol 2007; 107:125-26. 